\title{
Automated System for Recording the Results of Scientific Activity of Academic Institutions' employees
}

\author{
Svetlana Vlasova ${ }^{[0000-0003-1533-5850]}$ \\ Joint Supercomputer Center of Russian Academy of Sciences, - Branch of Federal State \\ Institution "Scientific Research Institute for System Analysis" of Russian Academy \\ of Sciences, Leninskiy pr., 32a, 119334, Moscow, Russia \\ vlas.svetlana2013eyandex.ru
}

\begin{abstract}
The article describes the automated system for creating and maintaining a database for recording the results of scientific activities of employees of academic institutions, developed by specialists of the Joint Supercomputer Center RAS. The information base of the system contains related data on the following classes of objects: persons (authors of publications and reports), organizations and their subdivisions; publications at analytical, monographic and summary levels; copyright certificates; scientific events (conferences, symposia, seminars); reports. The system reflects the sources of funding for scientific research, based on the results of which the works were published, as well as the affiliations of each author indicated in the articles. A distinctive feature of the system is the introduced concept of "equivalent" objects. Objects are considered equivalent if they are represented in the system by different metadata, but referring to the same physical entity. Such objects are "persons" corresponding to the same author with different spellings of the last name in the bibliographic descriptions of publications; organizations with different versions of names; articles which are published without changes in different languages. The system includes two modules - administrative and user. The administrative module is intended for entering and editing data. The user module of the system is a special search engine that searches for information, visualizes it, navigates through related resources and exports data.
\end{abstract}

Keywords ${ }^{1}$ : scientific works, bibliographic descriptions, automated system, database, search queries.

At present, each organization faces the task of keeping track of the scientific works of its employees. To accomplish this task, the scientific libraries of the Russian Academy

${ }^{1}$ CDSSK-2020: International Conference “Common Digital Space of Scientific Knowledge”, November 10-12, 2020, Moscow, Russia

EMAIL: vlas.svetlana201@yandex.ru (Svetlana Vlasova)

ORCID: 0000-0003-1533-5850 (Svetlana Vlasova)

(c) (1) (C) $\square 2021$ Copyright for this paper by its authors. Use permitted under Creative Commons License Attribution 4.0 International (CC BY 4.0)

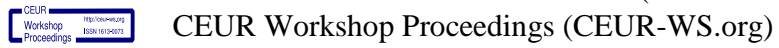


of Sciences previously kept card indexes of employees' works containing data on published articles, monographs, etc. With the development of computer technology, information and analytical systems have replaced the traditional card indexes of publications. These systems maintain databases of employees' works and provide users with access to them via the Internet [1-6].

In 2017, in the Library for Natural Sciences of the Russian Academy of Sciences, a standard automated system for the formation and support of a publication database was developed and introduced into technical operation [7]. The implementation of the system was based on Microsoft ASP.NET 4 technology on the Microsoft.NET Framework platform in the Microsoft Visual Studio 2018 development environment using the $\mathrm{C} \#$ programming language. Database of the system are supported by Microsoft SQL Server.

In 2019-2020 the system for supporting the database of scientific papers was further developed at the Joint Supercomputer Center of the Russian Academy of Sciences (JSCC RAS).

The system ensures the creation of the following interconnected objects:

$>$ publications at analytical and monographic levels;

$>$ sources (magazines, collections in which articles are published);

$>$ reports;

$>$ scientific events at which reports were made;

$>$ persons (authors of publications and reports);

$>$ organizations (places of persons work).

The system consists of two modules: administrative and user. The following processes are carried out in the administrative module (http://dirsmsc.ru/bd/adm.aspx):

$\checkmark$ entering and editing data about operators working with the system;

$\checkmark \quad$ input of new records of publications, reports, events, persons, organizations;

$\checkmark$ editing the metadata of all objects;

$\checkmark$ search and view of objects registered in the system;

$\checkmark$ creating groups of equivalent records.

Links of the "equivalent records" type are implemented between objects in the system. The objects connected in this way are perceived by the system as identical. The need to enter equivalent persons is due to the fact that the spelling of the surname and first name of the same author in different bibliographic descriptions may differ. Publication equivalence occurs when an article in the original language and its fully translated versions into another language are reflected in the database. Equivalence relations for organizations are established when the name of the organization is changed (for example, the Computing Center of the USSR Academy of Sciences and the Computing Center of the Russian Academy of Sciences).

Consider the process of entering publications and reports into the system. Entering data for a new publication begins with entering its authors in the order presented in the publication. If the author of the publication is already registered in the system, then the system will show the organizations related to it - the names of organizations that were registered earlier when entering the publications of this author. You must select (or input into the system) the organization that is indicated as the author's affiliation in this 
article. If the author is not in the system, it is necessary to register him (enter his surname and initials), as well as enter his affiliation.

After completing the input of authors, the system will provide a form for entering publication metadata: publication name, type of publication (article, monograph), source, year of publication, volume, number, pages, full text address, identifiers in external databases (DOI, WoS, Scopus), state assignment number, grant numbers (Fig. 1).

When entering the title of the publication, the system shows already registered publications by the same authors if it finds matches in the titles (by the first entered words). To link to the source have being entered (the edition where the article is published), it must be found by fragments of the title, and if it is absent, it must be registered in the system. After all the necessary metadata has been entered, the publication will be registered in the system.

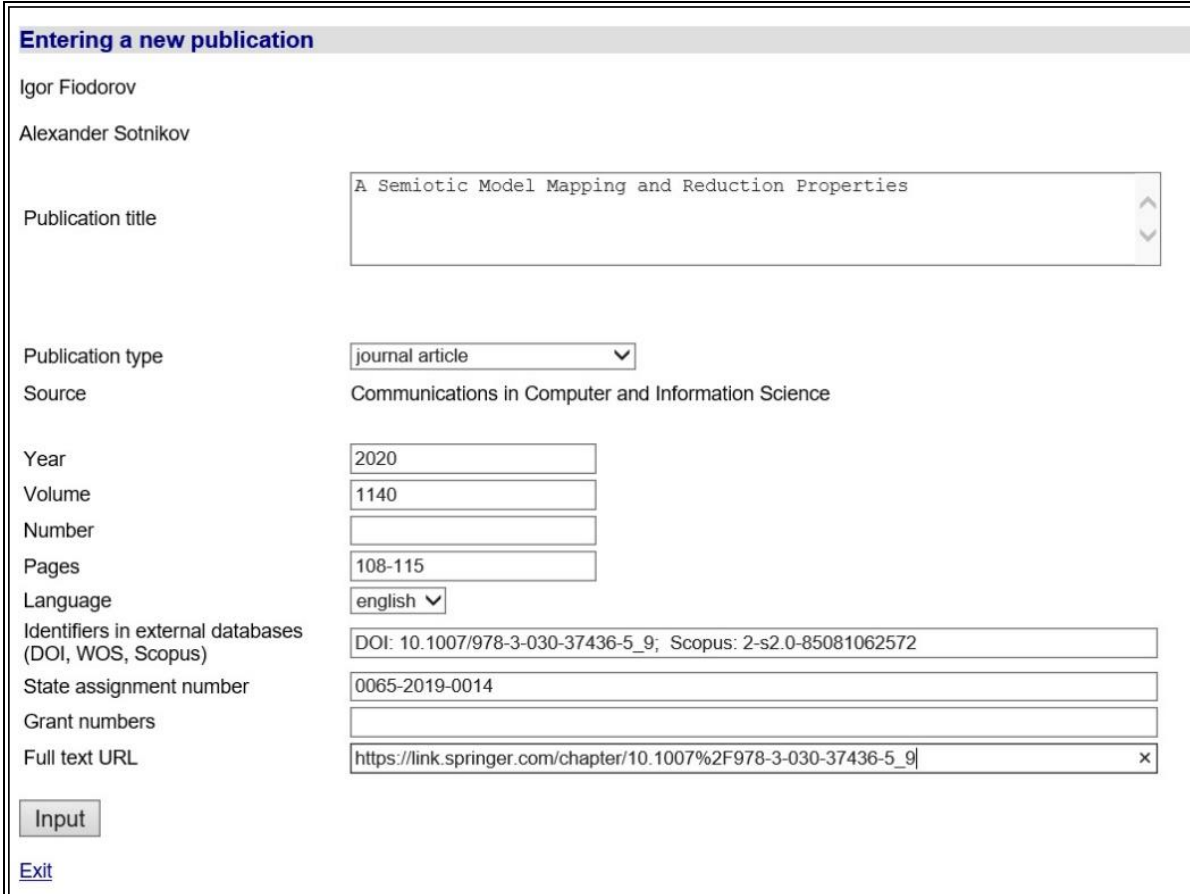

Fig. 1. Registration of publication.

Registration of a new conference report, as well as the registration of a new publication, begins with the input of authors. For each author of the report, the status is indicated: speaker or co-speaker. Then the system provides a form for entering the metadata of the report: the title, the language, the type of the report (plenary, sectional, poster, invited), event, links to the report presentation and video recording (Fig. 2).

The scientific event at which the report was presented must be linked to the report. Presence of the event in the system determines by its title fragments. If it is absent, a form is provided to enter the following metadata: the name of the event, the type of 
event (conference, seminar, symposium, meeting), the venue of the event (city and country), dates of the event, a link to the event website.

The metadata of organizations in the system is presented in the form of a hierarchical structure: an organization can include division that have departments, which, in turn, can include laboratories, etc. The system administrator enters the name of the organization, then the names of its divisions, then binds the names of departments to each division, etc.

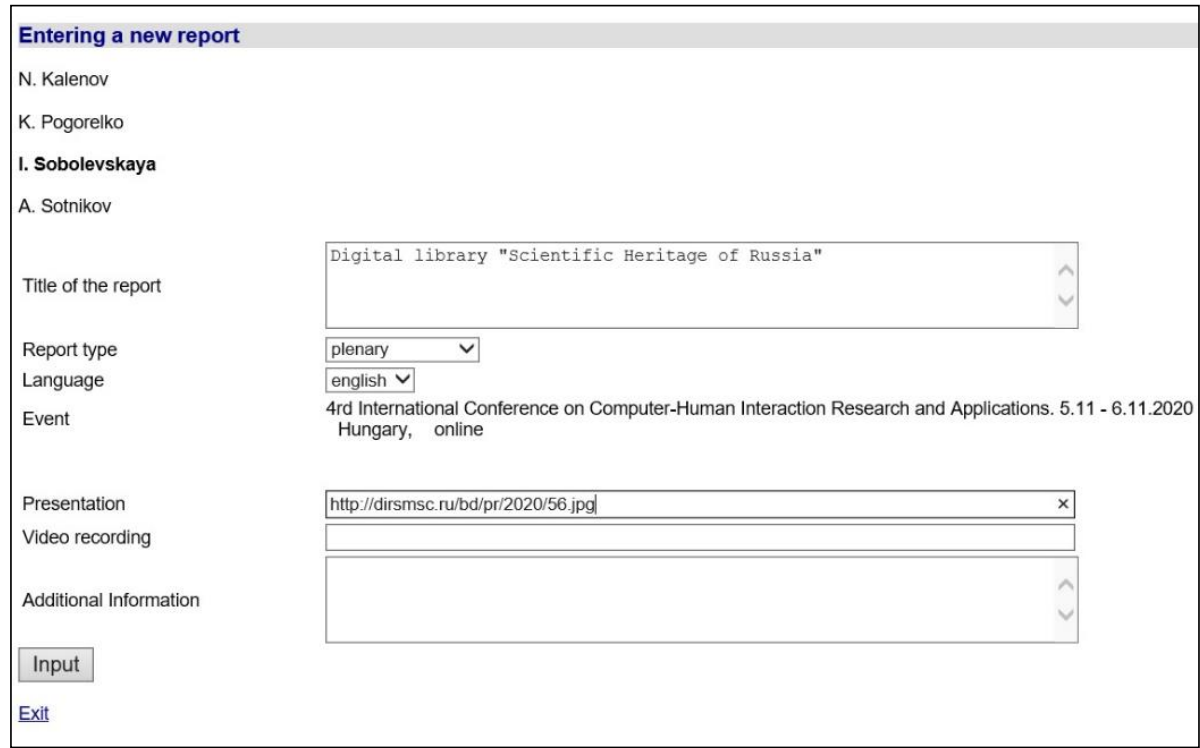

Fig. 2. Registration of report

The user block of the system (http://dirsmsc.ru/bd/) was created taking into account the experience of the author's previous developments $[8,9]$. It is a search engine that processes search queries of any complexity. To form a query in the search form (Fig. 3) terms are entered in one, two or three lines. Strings are connected by logical operators "AND", "OR", “AND NOT". Several terms can be entered in each line by connecting them with logical "AND" or "OR". It is possible to truncate the term on the right using the symbol "*". By default, words are linked by the "AND" operator, which can be changed to "OR". By default, strings are linked by an "AND" operator, which can be changed to "OR" and "AND NOT".

By default, in the search form in the first line the field "Person's surname" is selected, in the second - "Title of the publication", in the third - "Title of the report" (Fig. 3). The search query can be limited to the years of publications (reports) by selecting the required years from the "Year: from ... to ..." drop-down lists. Search results can be sorted forward or reverse order by year or alphabetically by descriptions of the records being found. By default, sorting is performed by year in reverse order (publications 
(reports) of the current year are displayed first). Also, in the search form, you can set the language of the found documents: Russian or English.

For each line of entered terms in the search form, the name of the area (field) in which the search should be performed is selected:

- Person's surname;

- Publication title;

- Title of the journal / collection;

- Title of the report;

- $\quad$ Event (name, country, city);

- Organization;

- Identifier in external databases.

It is possible to customize the issuance of the found information by selecting the required line from the "Show" drop-down list in the search form:

- Publications and reports;

- Publications;

- Reports;

- Journals / collections;

- Events;

- Persons;

- Organization.

By default, the option "Publications and reports" is selected in the search form. The result of running search queries is displayed on the screen in portions, the size of which is specified in the "Show ... by ..." drop-down list (by default - 20 documents per page). If all search fields are left empty and click on the "Search" button, the system will display all registered objects in accordance with the selected "Show" option.

In Fig. 3 an example of a request for a search for joint English publications by the authors "Sotnikov", "Sobolevskaya" and "Kalenov" for 2020 is given. On this request, the system finds 3 publications that are issued in the form of standard bibliographic descriptions. Publication title, authors and journal title are an active links in these descriptions. The publication title will be an active link if the publication's metadata contains an address to its full text.

The link on the name of the source (journal, collection) allows you to get a list of all articles registered in the system and published in this source.

When clicking on the link from the author's surname, the user will receive the following information: all equivalent records for this person, its identifiers in the ORCID, RSCI, Scopus, WoS systems. Also, the names of all organizations related to this person are issued. Then the system determines the total number of publications registered in the system and displays its descriptions (Fig. 4).

The link from the name of the organization (division, department) allows you to go to the articles of all persons belonging to this organization (division, department).

The system provides the ability to unload the bibliographic descriptions of the publications required by the user represented in two types: standard text form or into a structured file of CSV format. Records of files of the first type can be included in the 
list of cited bibliography by simple copying, records of the second - in the EXCEL table for subsequent use in the user's personal library.

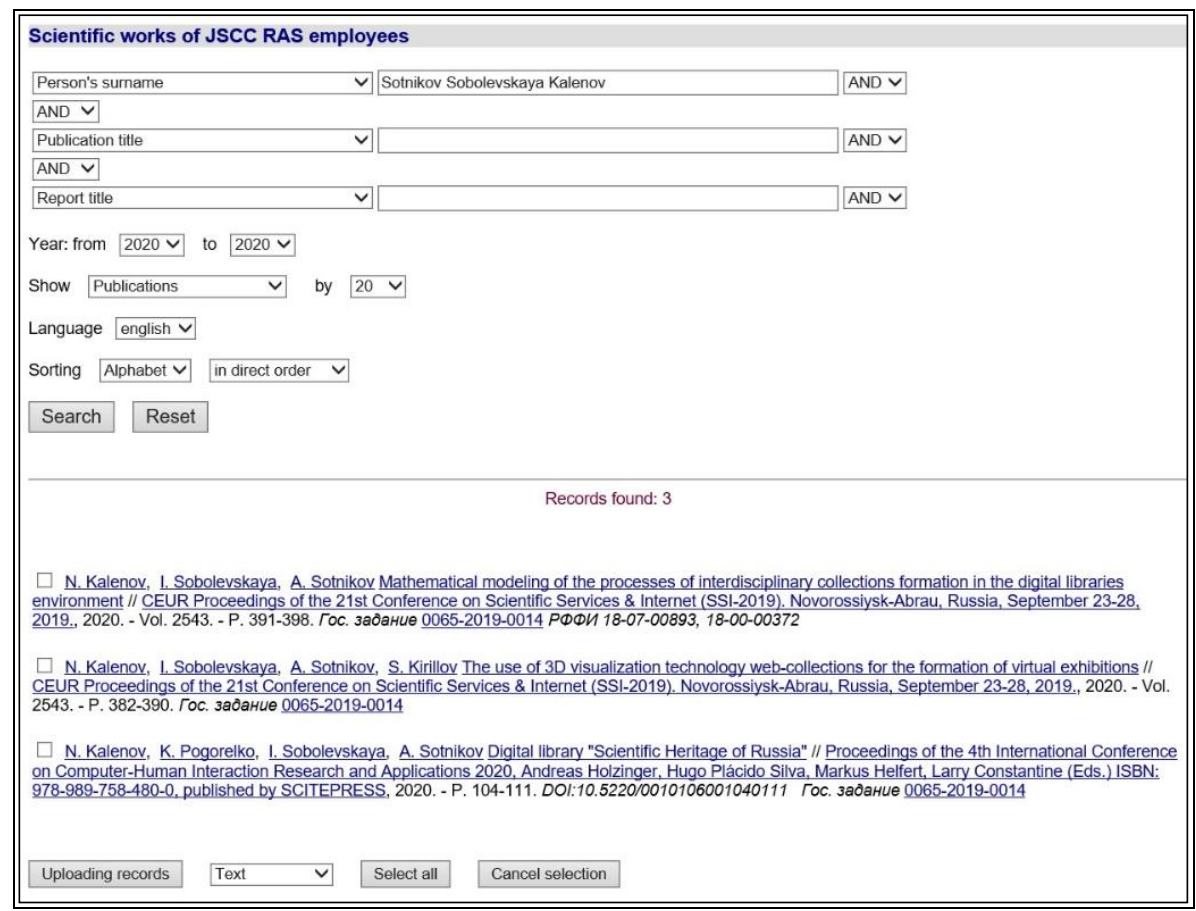

Fig. 3. Search engine form. An example of a request to search for publications

To unload bibliographic records, the user marks the publications he needs, selects the required format at the bottom of the viewing page and clicks the "Unload records" button. You can mark records on any page of viewing the found publications; when you go through the pages, the "check marks" are saved. You can also click the "Upload Records" button on any of the pages. After clicking it, the unloaded file of the selected structure is shown in a new window. The bibliographic descriptions of publications can be copied by the user to their computer with simple copy / past options. If the user selects the CSV format, the button "Download file" appears on the screen, after clicking on which the records are uploaded to a file with the CSV extension on the user's PC, upon opening which a table with the following columns is generated in EXEL: authors, publication title, source title, the year of publishing, volume, number, pages, identifiers in external databases, full text address.

In addition to the abovementioned search for publications in the user block of the system, the search and viewing of reports is similarly implemented. The request to search for reports presented in 2019 which titles contain the term "3D" is shown in Fig. 5. 


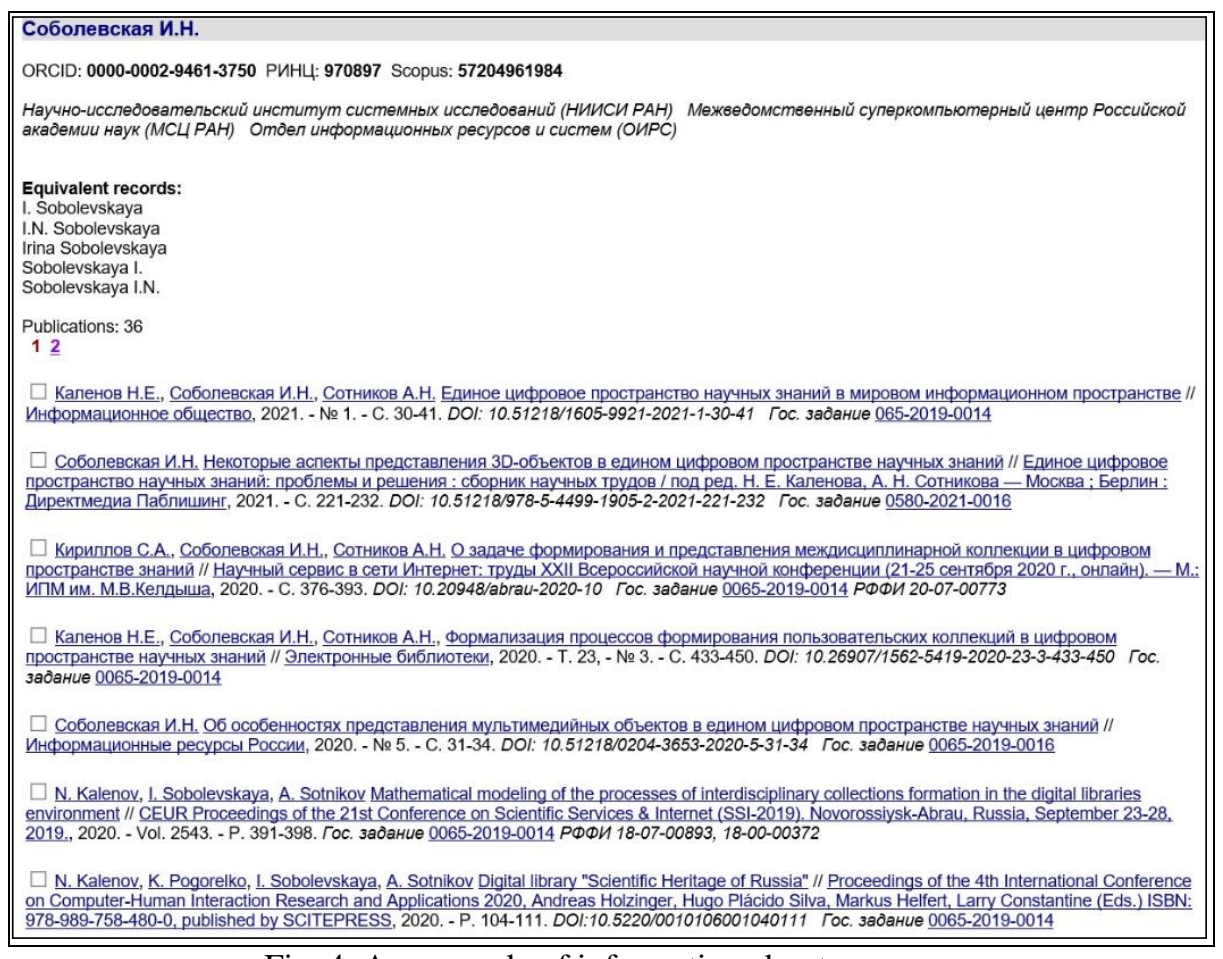

Fig. 4. An example of information about a person

As a result of the search, the system displays a list of the found reports. Each entry contains a list of the authors of the report (the speaker is in bold), the title of the report and a description of the event (title, dates of the event, location of the event). The names of the authors are active links, the transition to which will provide the issuance of information about the author and all the reports of this author registered in the system. The name of the event is a link to the event website. At the bottom of the description of the report there is a link "Presentation of the report", which allows you to download the presentation on the user's PC.

The system allows you to unload selected report records in text format and CSV format. The procedure for selecting and unloading records of reports is completely identical to that described above for unloading publications. When unloading in CSV format, an EXEL table is formed with the following columns: authors, report title, event title, dates of the event, country, city, event website.

At present, the system is successfully operating in the technological mode at JSCC RAS. The users of the system are researchers at the JSCC RAS. 335 persons from 51 organizations are registered in the system; 790 articles which have been published in 358 editions. In addition, this year began inputting the reports made at scientific events. There were registered 33 events and 56 reports made in 2018-2021.

The work was carried out at the JSCC RAS - Branch of Scientific Research Institute for System Analysis of RAS, within the framework of state assignment No. 0580-20210014. 


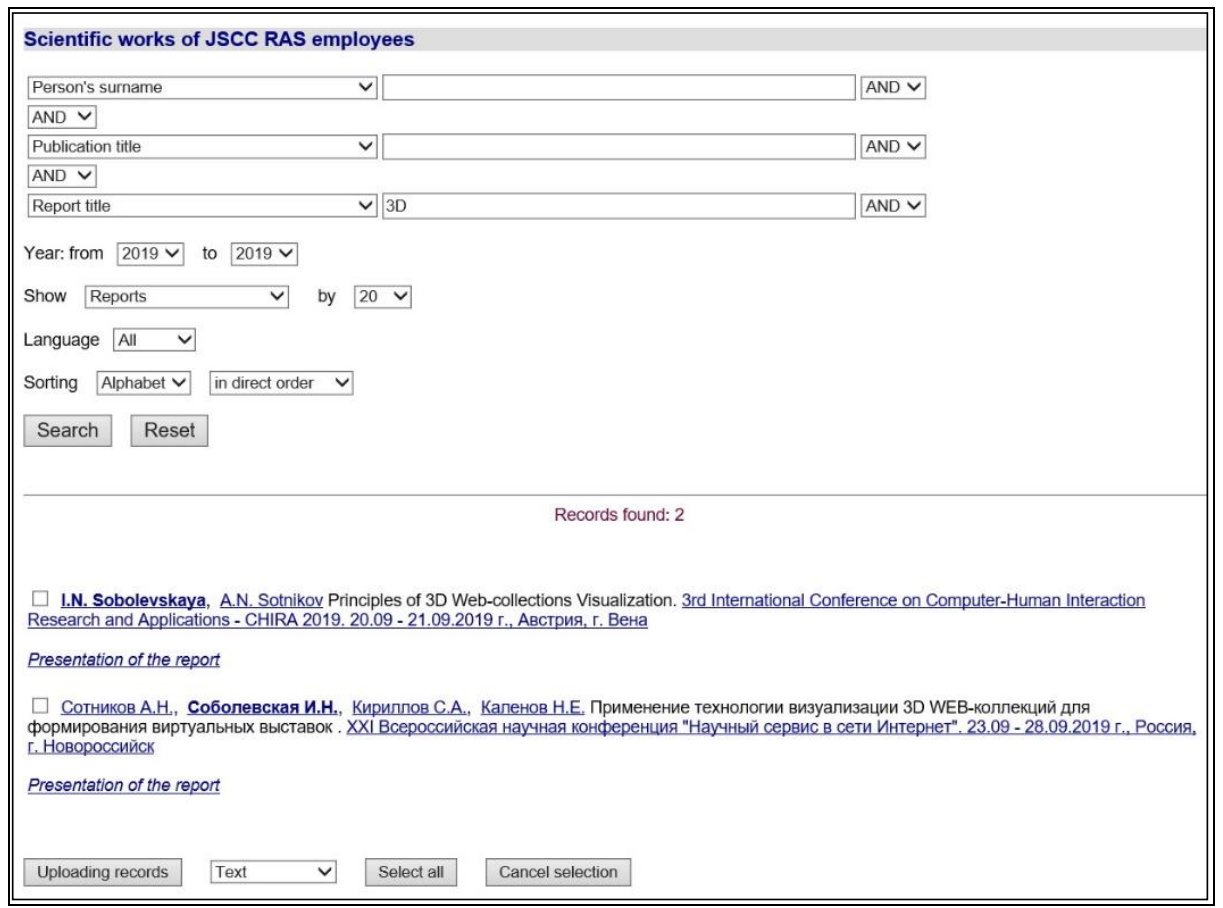

Fig. 5. An example of a request to search for reports

\section{References}

1. Zakharova, S.S., Gureeva, Yu.A.: Nauchnye publikatsii: ot kartoteki trudov do bibliograficheskikh profiley. Bibliosfera 2. S. 85-89 (2017). https://doi.org/10.20913/1815-31862017-2-85-89.

2. Mazov, N.A., Gureev, V.N.: Sozdanie bazy dannykh trudov sotrudnikov organizatsii kak osnovy dlya dostovernogo bibliometricheskogo analiza. In: Trudy GPNTB SO RAN (9). S. 103-109 (2015).

3. Vasilenko, E.A., Panfilov, V.I., Zhukov, D.Yu., Sivukha, D.V.: Razrabotka naukometricheskoy bazy dannykh publikatsionnoy aktivnosti uchenykh RKhTU im. D.I. Mendeleeva. Nauchno-Tekhnicheskaya Informatsiya. Ser. 1. 11. S. 26-30 (2013).

4. Stolyarov, R.A., Chugreev, V.L.: Avtomatizirovannaya sistema ucheta rezul'tatov intellektual'noy deyatel'nosti v nauchnoy organizatsii. Voprosy Territorial'nogo Razvitiya 6 (26). S. 4 (2015).

5. Kochergina, T.A., Iskhakova, L.D., Kalenov, N.E., Yakshin, M.M.: Baza dannykh "Trudy sotrudnikov NTsVO RAN" kak chast' informatsionno-poiskovoy sistemy "Volokonnaya optika". Sistemy i Sredstva Informatiki 23(2). S. 284-296 (2013). https://doi.org/10.14357/08696527130218

6. Levchenko, O.I., Solov'ev, A.V.: Formirovanie bazy dannykh publikatsiy sotrudnikov Instituta fiziki tverdogo tela RAN. In: Informatsionnoe Obespechenie Nauki: Novye Tekhnologii: Sbornik nauchnykh trudov / Kalenov N.E., Tsvetkova V.A. (red.). M.: BEN RAN. S. 215-221 (2015). 
7. Vlasova, S.A.: Avtomatizirovannaya sistema podderzhki korporativnoy bazy dannykh nauchnykh publikatsiy. Programmnye Produkty, Sistemy i Algoritmy 2. S. $42-46$ (2018). https://doi.org/10.15827/2311-6749.27.311.

8. Vlasova, S.A., Kalenov, N.E.: Informatika v akademicheskoy biblioteke. Sistemy i Sredstva Informatiki 26 (3). S. 162-178 (2016). https://doi.org/10.14357/0869652716031.

9. Vlasova, S.A., Kalenov, N.E.: Internet-katalog Biblioteki po estestvennym naukam Rossiyskoy akademii nauk kak spetsial'naya informatsionno-poiskovaya sistema, orientirovannaya na kvalifitsirovannogo pol'zovatelya. Sistemy i Sredstva Informatiki 29 (1). S. 8695 (2019). https://doi.org/10.14357/08696527190108. 